\title{
A STUDY OF FACTORS PROMOTING PYCNIDIUM-FORMATION IN SOME SPHAEROPSIDALES
}

\author{
LEON H. LeONIAN \\ (Received for publication March 3, I923)
}

\section{INTRODUCTION}

A fungus, like any living organism, is a composite of hidden potentialities which may not manifest themselves unless subjected to the proper environmental stimuli. The same fungus under the influence of one group of environmental factors may show the characteristics of one specific organism, but when subjected to the action of another group of factors it may reveal different morphological peculiarities. It is highly essential, therefore, to investigate the physiological relations of fungi in order to classify them properly. The Sphaeropsidales, which contain a large number of interesting as well as economically important forms, have received but scanty attention from physiological investigators. Although the literature on the pathogenic relationship of these fungi is quite extensive, yet, since the papers emphasize the fungi as causal organisms of disease rather than as complex living things possessing many other characteristics, such accounts are necessarily specific in nature. It is the object of this paper, therefore, to study under controlled laboratory conditions some twenty representative members of the Sphaeropsidales and to organize in groups the typical reactions of these forms particularly from the standpoint of pycnidiumproduction.

This work has been done in the cryptogamic laboratory of the University of Michigan under the direction of Dr. C. H. Kauffman, for whose inspiring guidance I wish to express my deep gratitude.

\section{ORGANISMS}

The following is a list of the organisms which were used in the experiments outlined in this paper. Unless otherwise stated, all of them have been collected, identified, and placed in pure culture by the writer.

I. Phyllosticta opuntide Sacc. \& Speg. On Opuntia sp. State College, N. M., January, 1920.

2. Phoma urens E. \& E. On Populus sp. Chelsea, Mich., Mav, I92 I.

3. Sphaeronema pruinosum B. \& C. On Rhus glabra L. Ann Arbor, Mich., August, I921.

4. Sphaeronema spurium (Fr.) Sacc. On Prunus americana Marsh. Ann Arbor, Mich., June, I921.

5. Vermicularia circinans Berk. On the bulbs of Allium Cepa L. Ann Arbor markets, October, I920. 
6. Plenodomus destruens Harter. On Ipomoea Batatis Poir. Subcultures made from material sent to Ann Arbor by Dr. L. L. Harter.

7. Cytosporella mendax Sacc. \& Roum. On branches of Quercus sp. Chelsea, Mich., May, I92I.

8. Naemosphaera sp. On leaves of Typha sp. Francisco, Mich. Collected by Jee Bonar, I 920.

9. Coniothyrium concentricum (Desm.) Sacc. On leaves of Yucca macrocarpa Engelm. State College, N. M., January, I920.

10. Ascochyta nymphaeae (Passer.) Hedw. On leaves of Nymphaea advena

Ait. Whitmore Lake, Mich., October, I920.

I I. Kellermania yuccagena E.\&E. On leaves of Yucca glauca Nutt. State College, N. M., January, 1920.

12. Stagonospora collapsa (Cke. \& Ell.) Sacc. On twigs of Acer Negundo L.

Ann Arbor, Mich., June, 1921.

I3. Stagonospora gigantea Heald \& Wolf. On leaves of Yucca elata Engelm.

State College, N. M., January, I 920.

14. Hendersonia sp. On leaves of Rhus glabra L. Ann Arbor, Mich., June, I921.

15. Sphaerographium fraxini (Pk.) Sacc. On branches of Fraxinus americana

L. Ann Arbor, Mich., July, I92 I.

16. Endothia parasitica (Murr.) Anders. On branches of Castanea dentata

(Marsh) Borkh. Syracuse, N. Y. Collected and identified by Dr. A. H. W. Povah, November, 1920.

17. Ollula sp On leaves of Rhus glabra L. Ann Arbor, Mich., October, I920.

I8. Melanconium betulinum Schm. \& Kz. On branches of Betula sp. Terre Haute, Ind., April, I92 I.

19. Pestalozzia guepini Desm. On leaves of Hevea brasiliensis Muell. Kisaram, Sumatra, August, 1918. Collected, identified, and isolated by Dr. Carl D. La Rue.

20. Steganosporium acerinum $\mathrm{Pk}$. On branches of Acer grandidentatum Nutt.

Organ Mountains, N. M., June, I920. Identified by Mr. Andrew Archer.

\section{Nutrient Media}

It was realized that a purely synthetic nutrient solution would probably fail to induce uniformly good pycnidium-formation in all the foregoing twenty organisms, because it usually seems to lack the mysterious something that is found associated with certain complex organic media. Consequently an effort was made to find a suitable organic preparation that could be combined with some other favorable nutrient solution. Malt extract has been widely used in Europe and found advantageous for the purpose in question. It forms the chief constituent of Blakeslee's agar which has been found to be an ideal medium for the culture of Mucors. Malt extract was selected, therefore, to furnish the unknown factor mentioned above. Since, furthermore, maltose is the dominating type of sugar in the grains which constitute favorable culture media for a large number of fungi, maltose was chosen as the chief carbohydrate source. Peptone was found preferable for the nitrogen supply. With dihydrogen potassium phosphate and magnesium sulphate serving as sources for the essential inorganic salts, there remained only the task of establishing the proper proportions of the various ingredients until a good nutrient solution could be obtained. The following 
formula was found to be the best, and this has been used exclusively throughout the experiments outlined in this paper:

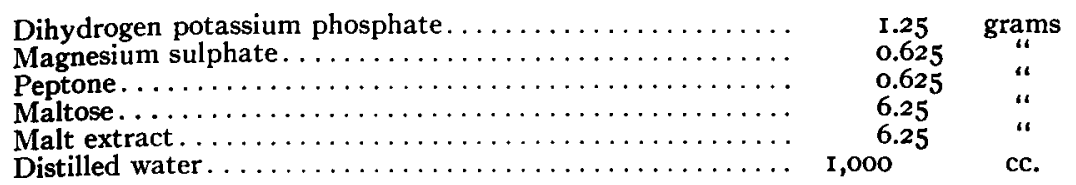

The solution was heated in a double boiler or in Arnold's sterilizer for fifteen minutes, filtered, and then autoclaved at ten pounds' pressure for fifteen minutes. If a solid medium is desired, I.5-2 percent agar agar may be added to the solution. The agar agar should be melted in a separate lot of water before it is added to the nutrient portion.

\section{Methods}

Saprolegnia and other related fungi that normally live in water can best be grown and studied in aqueous solutions or in liquid media, whereas wood- and vegetable-inhabiting organisms like the Sphaeropsidales require solid media for their notmal development. Klebs and his followers experienced no trouble in growing algae or water molds in liquid media and in transferring them from one solution to another. But how could the same method be used in the case of fungi growing in test tubes and on solid substrata; and how could these cultures be washed and transferred to another solution? Coons (4) used filter-paper cones as a base for his cultures. He placed these cones in glass capsules which contained a nutrient solution, and the filter paper, remaining moist through capillary action, served as a satisfactory substratum. The same method was at first tried by the writer, but many organisms failed to confine themselves to the cone, and, growing down into the solution, filled the capsules with a mass of dense and moist mycelium. A modification of Coon's method which the writer has described in another paper ( $\mathrm{r} 7$ ) gave comparatively better results. Filter-paper cups were made and then placed in capsules which contained distilled water. After a thorough sterilization in the autoclave, a nutrient agar was poured into these cups. When the fungi were transferred to this agar, they confined themselves largely to the cup. This method, however, was not found to be practical for the requirements of the present investigations; consequently, a method was developed by which pieces of filter paper were folded into small pads and placed in a nutrient solution where they absorbed and retained enough food to serve the needs of the growing organism, thus eliminating the tendency of the mycelium to grow into the liquid. Subsequent experiments proved this an excellent procedure. In this method, circular glass capsules $5 \mathrm{~cm}$. in diameter and of 25 -cc. capacity, and Whatman filter paper no. I, I2.5 cm., take the place of test tube and agar agar respectively. Each sheet of filter paper is cut into four equal parts, each of which is 
moistened with distilled water and then folded to give it a disc-like appearance, two centimeters in diameter and three to four millimeters in thickness. This moist pad is then placed in the palm of one hand and firmly pressed with the thumb of the other hand, thus giving it a concave-convex form. Then it is dried either in the open air or in a drying oven, placed in the capsules with the concave side down, and sterilized in the autoclave. A few cubic centimeters of any desired solution may then be added. Each pad absorbs about one half cc. of solution, while a part of the remaining liquid is attracted to and retained in the hollow of the pad. This pocket-like space draws upon the remainder of the solution in the capsule as the growing organism gradually'uses up the ingredients. The fungi make a good growth on these filter-paper pads, eventually covering them with numerous fruiting bodies. The entire culture with its filter-paper pad can be removed at any time from the capsule by means of a flamed forceps, transferred to a series of larger capsules containing distilled sterile water, washed thoroughly, and transferred again to another solution or to distilled water in another capsule. All these operations can be performed without injuring the mycelium. This is an important point that should not be overlooked, because, if mycelium is injured by cutting or otherwise, other factors will'enter into the experiments and complicate matters.

The filter-paper-pad culture has another advantage: after the fungus has completed its growth and reproduction, the pads can be taken out of the capsules, dried in the open air, and pasted on cardboards, thus forming a herbarium of pure cultures which, in most cases, retain their natural condition and individual characteristics perhaps for a long time.

Isolations. The dilution method of single-spore cultures has been followed during the isolation of all the organisms listed in this paper.

Symbols. All data given in the tables of this paper are expressed by numerals; the Roman numerals of each table represent, each, one type of experimentation, while the Arabic numerals indicate the quantity of fruit bodies formed. The number of pycnidia is expressed on the percentage basis because it affords a wider margin for making estimates. The Arabic numeral 5 is taken as the smallest unit, and 100 as the largest. The numeral 5 , therefore, means very poor, and, according to the nature of the fungus, it may represent only one, or as many as forty or fifty fruit bodies. Similarly, Ioo means very good, and may represent less than fifty or many more than one hundred pycnidia in each culture. No attempt was made to count the actual number of fruit bodies, for, after all, it is the relative quantity of pycnidia that is important. After one has made thousands of cultures and has become accustumed to the behavior of the individual organisms under their best and their poorest conditions for fruiting, one does not find it very difficult to make comparative estimates with a good deal of accuracy. 


\section{The Experiments}

The experimental work is divided into two phases: first, the preliminary work, in which such factors as light, temperature, oxygen supply, solidity of the substratum, transpiration, adsorption, and the reaction of the medium have been tested for the purpose of clearing the way to the more definite portion of the problem; second, the principal work, which deals for the most part with food-concentration and its relation to pycnidium-formation in these fungi.

\section{Light}

Two sets of cultures were made; one was kept in diffused light, and the other was placed in a large dark chamber five feet wide, six feet long, and six feet high. Holes in the sides and on the top provided ample circulation of air, although they were loosely plugged with cotton so as to prevent the entrance of light. This chamber was in the same room where the experiments with the diffused light were conducted, and had, therefore, approximately the same temperature. Thus, all factors except light being alike, the results shown in the first two columns of table I are to be attributed to the presence or the absence of light.

I. Cultures were kept in diffused light and at ro $\mathrm{m}$ temperature.

ii. Cultures were kept in the dark and at room temperature.

III. Cultures were kept at ordinary room temperature for twenty-four hours; then they were transferred to the dark at a constant temperature of $30^{\circ} \mathrm{C}$.

IV. Cultures were kept at ordinary room temperature for twenty-four hours; then they were transferred to the dark at a constant temperature of $8^{\circ} \mathrm{C}$.

The keeping of the cultures at ordinary room temperature for a given length of time before transferring them to a high or to a low temperature

TABLE I. The Effect of Light and Temperature

\begin{tabular}{|c|c|c|c|c|}
\hline Organisms & I. Light & II. Dark & III. $30^{\circ} \mathrm{C}$. & IV. $8^{\circ} \mathrm{C}$. \\
\hline 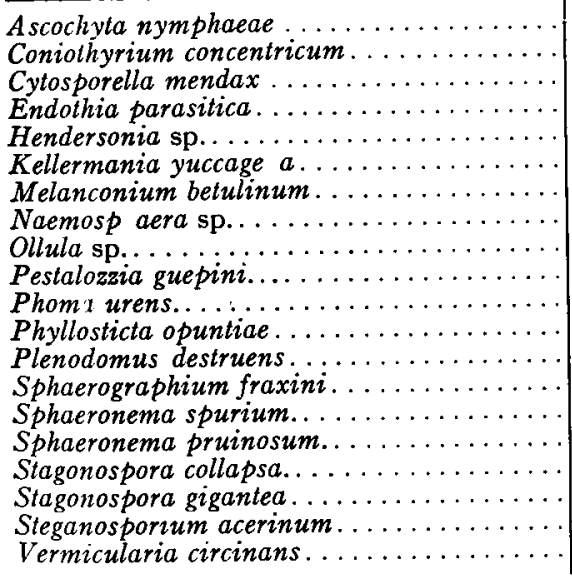 & $\begin{array}{l}60 \\
25 \\
25 \\
15 \\
20 \\
15 \\
20 \\
25 \\
10 \\
20 \\
10 \\
40 \\
30 \\
10 \\
20 \\
25 \\
20 \\
10 \\
15 \\
40\end{array}$ & $\begin{array}{r}30 \\
10 \\
20 \\
15 \\
0 \\
10 \\
20 \\
25 \\
10 \\
0 \\
5 \\
5 \\
30 \\
0 \\
5 \\
5 \\
10 \\
10 \\
10 \\
30\end{array}$ & $\begin{array}{r}65 \\
15 \\
35 \\
30 \\
0 \\
20 \\
0 \\
40 \\
10 \\
20 \\
15 \\
40 \\
35 \\
5 \\
20 \\
0 \\
20 \\
10 \\
15 \\
30\end{array}$ & $\begin{array}{r}45 \\
10 \\
5 \\
5 \\
0 \\
5 \\
0 \\
0 \\
5 \\
0 \\
0 \\
0 \\
5 \\
0 \\
5 \\
0 \\
10 \\
5 \\
5 \\
20\end{array}$ \\
\hline
\end{tabular}


was for the purpose of eliminating any possible hindering influence exerted by the other temperatures upon the germination of the spores.

Only two organisms, Hendersonia sp. and Sphaerographium fraxini, failed to form pycnidia in the dark, and while Plenodomus destruens, Naemosphaera sp., Stagonospora gigantea, Endothia parasitica, Melanconium betulinum, and Ollula sp. remained indifferent, the amount of fruiting of the rest of the organisms was reduced.

\section{Temperature}

The chief reason for working with the temperature factor at all was to supplement the experiments with light, and no attempt was made, therefore, to determine the temperature limits of the organisms. An examination of column III of table I shows that in some cases a trigher temperature not only replaces the effect of light, but can become a more efficient agent for the promotion of fruiting. Sphaerographium fraxini, which failed to fruit in the dark and at room temperature, was able to form a few pycnidia at $30^{\circ} \mathrm{C}$., even in the absence of light. Ascochyta nymphaeae, Cytosporella mendax, Endothia parasitica, Kellermania yuccagena, Naemosphaera sp., Plenodomus destruens, and Phoma urens formed more pycnidia at a higher temperature in the dark than they did in the light and at room temperature. Coniothyrium concentricum, Sphaerographium fraxini, and Vermicularia circinans formed fewer pycnidia at $30^{\circ} \mathrm{C}$. than they did in the light; Hendersonia sp., Melanconium betulinum, and Sphaeronema pruinosum failed to fruit, while the remaining organisms were indifferent.

Hendersonia sp., Melanconium betulinum, Naemosphaera sp., Pestalozzia guepini, Phoma urens, Phyllosticta opuntiae, Sphaerographium fraxini, and Sphaeronema pruinosum failed to fruit at $8^{\circ} \mathrm{C}$. in the dark. When, however, these eight organisms were transferred into the light but still kept at $8^{\circ} \mathrm{C}$., all of them formed pycnidia after a time.

\section{Oxygen Supply}

When one is working with hundreds of cultures at a time, there is always a natural tendency to crowd the cultures in such a way as to interfere with a free air supply. In order to ascertain, therefore, the influence of a lack of free exchange of air and a consequent accumulation of carbon dioxid upon the fruiting of the organisms, the following experiment was arranged: two series of cultures having been prepared, one was used as a check and kept in the open room, while the other was placed in a desiccator sealed with vaseline. The use of the desiccator eliminated the water vapor which otherwise would have been present in the closed compartment. The glass capsules contained sufficient nutrient solution to keep the cultures well supplied with food and moisture throughout the experiment. Table 2 shows the results after one month.

I. Check: cultures kept in the open room.

II. Cultures kept in the desiccators. 
TABLE 2. The Effect of Reduced Oxygen Supply

\begin{tabular}{|c|c|c|}
\hline Organisms & I. Check & II. In Sealed I \\
\hline Ascochyta nymphaeae............... & 60 & \\
\hline Coniothyrium concentricum............. & 25 & \\
\hline Cytosporella mendax $\ldots \ldots \ldots \ldots \ldots \ldots \ldots \ldots$ & 25 & \\
\hline 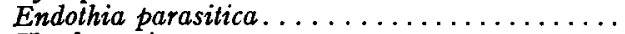 & I5 & \\
\hline$\ldots \ldots \ldots \ldots \ldots \ldots \ldots$ & 20 & \\
\hline 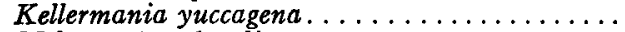 & Io & \\
\hline Melanconium betulinum . . . . . . . . . . . & 20 & \\
\hline Naemosphaera sp $\ldots \ldots \ldots \ldots \ldots \ldots \ldots \ldots \ldots$ & 25 & \\
\hline Ollula $: \mathbf{p} . \ldots \ldots \ldots \ldots \ldots \ldots \ldots \ldots \ldots \ldots \ldots$ & Io & \\
\hline Pestalozzia guepini. ................... & 20 & \\
\hline 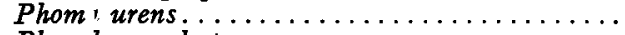 & 10 & \\
\hline Plenodomus des ruens. . . . . . . . . . . . & 30 & \\
\hline Phyllosticta opuntiae. . . . . . . . . . . . & 40 & \\
\hline Sphaerographium fraxini............... & 15 & \\
\hline 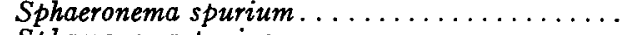 & 20 & \\
\hline Sphaeronema pruinosum. . . . . . . . . . & 25 & \\
\hline Stagonospora collapsa $\ldots \ldots \ldots \ldots \ldots \ldots \ldots$ & 20 & \\
\hline Stagonospora gigantea . . . . . . . . . . . & 10 & \\
\hline Steganosporium acerinum . . . . . . . . & $\mathbf{I} 5$ & \\
\hline cir & 40 & \\
\hline
\end{tabular}

It seems that free access of air is a very important factor for pycnidiumformation in many species, although a number of others remained quite indifferent to a limited supply of oxygen.

\section{Adsorption}

It might be supposed that the use of filter paper would result in the adsorption by the fibers of filter paper of some of the molecules of the nutrient solution. Consequently some experiments were set up to test the adsorption effect, if any, during the development of the organisms. Shredded filter paper, powdered Jena glass, and agar agar were used. A number of glass capsules, each containing Io $\mathrm{cc}$. of the nutrient solution, were prepared and divided into four groups and treated as follows:

I. Check: Io cc. of nutrient solution in glass capsules.

II. Io cc. of nutrient solution plus 0.15 gram of agar agar.

III. Io cc. of nutrient solution and one gram of shredded filter paper.

IV. Io cc. of nutrient solution plus I 5 grams of powdered Jena glass.

It is evident that adsorption of the molecules of food substances failed to be a clear-cut factor in these experiments (table 3 ). So long as there is a sufficient quantity of water present, adsorption phenomena can be disregarded. It was noticed, however, that, in case of cultures in which filter paper and powdered glass were used, growth ceased after the free water evaporated; in spite of the fact that the substrata were still wet, the water molecules became so strongly adsorbed, especially by the particles of the powdered glass, that the fungi were unable to obtain the necessary moisture. Similarly, when agar agar cultures lost part of their water, the adsorption became so active that the further growth of the organisms was arrested. 
TABLE 3. The Effect of Adsorption

\begin{tabular}{|c|c|c|c|c|c|}
\hline \multirow[b]{2}{*}{ Organisms } & \multicolumn{2}{|c|}{ I. Check } & \multirow{2}{*}{$\begin{array}{l}\text { II. Plus } \\
\text { Agar }\end{array}$} & \multirow{2}{*}{$\begin{array}{l}\text { III. Plus } \\
\text { Filter } \\
\text { Paper }\end{array}$} & \multirow{2}{*}{$\begin{array}{l}\text { IV. Plus } \\
\text { Powdered } \\
\text { Glass }\end{array}$} \\
\hline & $\begin{array}{l}\text { (a) On Sur- } \\
\text { face of } \\
\text { Solution }\end{array}$ & $\begin{array}{l}\text { (b) Sub- } \\
\text { merged }\end{array}$ & & & \\
\hline A scochyta nymphaeae. . . ...... & 30 & 0 & 40 & 50 & 50 \\
\hline Coniothyrium concentricum. & 75 & 75 & 75 & 60 & 75 \\
\hline Cytosporella mendax .......... & 25 & 0 & 75 & 55 & 75 \\
\hline Endothia parasitica.. & 35 & Io & 35 & 35 & 40 \\
\hline Hendersonia sp......... & 20 & Io & 30 & 50 & 40 \\
\hline Kellermania yuccagena.. . & 40 & 25 & 30 & 25 & 25 \\
\hline Melanconium betulinum. & 20 & o & 40 & 40 & 35 \\
\hline Naemosphaera sp...... & 20 & o & 50 & 50 & 50 \\
\hline Ollula sp... . . . . . . & 25 & 5 & 30 & 40 & 45 \\
\hline Pestalozzia guepini... . & 75 & 0 & 75 & 70 & 65 \\
\hline Phoma urens.......... & 20 & $\mathbf{5}$ & 40 & 40 & 45 \\
\hline Plenodomus destruens. . & 40 & 70 & 50 & 40 & 50 \\
\hline Phyllosticta opuntiae...... & 25 & 0 & 50 & 70 & 50 \\
\hline Sphaerographium fraxini. . & o & 0 & 30 & 40 & - \\
\hline Sphaeronema spurium... . & Io & & 15 & I5 & 15 \\
\hline Sphaeronema pruinosum.. & 25 & Immature & 75 & 75 & 75 \\
\hline Stagonospora collapsa... & 75 & o & 75 & 80 & 80 \\
\hline Stagonospora gigantea.... & 30 & & 25 & 20 & 30 \\
\hline Steganosporium acerinum.. & 25 & Immaturè & 50 & 40 & 45 \\
\hline Vermicularia circinans..... & 40 & Immature & 50 & 30 & 60 \\
\hline
\end{tabular}

\section{Transpiration}

Oxidation processes play an important rôle in the reproduction of fungi, but the degree of oxygen requirement varies with the specificity of the organism. Liquids contain less available oxygen than solid substrata, consequently some organisms form no fruit bodies when submerged, while others reproduce with equal ease both above and under water. An examination of column $\mathrm{I} b$ of table 3 shows that eight organisms fruited under water and matured their spores, three others formed immature pycnidia, and in the case of the remaining organisms no fruit bodies were formed under water. Plenodomus destruens gave rise to more fruit bodies under water than it did above the surface of the solution, while Coniothyrium concentricum formed pycnidia with equal ease both above and within the nutrient solution.

\section{Solidity of Substratum}

A comparison of column $\mathrm{I} a$ of table 3 with columns II, III, and IV shows that liquid media are less favorable for producing pycnidia than media which have been made more or less solid by addition of agar agar, filter paper, or powdered glass. Coniothyrium concentricum, Endothia parasitica, Kellermania yuccagena, Pestalozzia guepini, Stagonospora collapsa, and Stagonospora gigantea were the only organisms that remained unaffected by the liquid medium. The significance of this fact will be discussed later. 


\section{Reaction of Media}

Alkalinity. Alkalinity of the medium here used can not be considered an analyzable factor, because when enough sodium hydroxid was added to the solution to test even as high as -20 (Fuller's scale, phenolphthalein indicator), oxidation changes going on in the medium reduced the reaction of the solution to the neutral point within a few days.

Acidity. Since the use of hydrochloric acid, even in minute amounts, proved uniformly toxic to the organisms, tartaric acid was resorted to for testing approximate acid tolerance. Two series of standard nutrient solution ${ }^{1}$ were prepared. Tartaric acid, in such concentrations as to test $\mathrm{N} / 5$ and $\mathrm{N} / \mathrm{IO}$ acid, was added to these series. It was found that only eight organisms, namely, Cytosporella mendax, Endothia parasitica, Hendersonia sp.,. Melanconium betulinum, Ollula sp., Pestalozzia guepini, Plenodomus destruens, and Stagonospora collapsa formed fruit bodies, and then only a few, in the more acid solution, while only four fungi, Phyllosticta opuntiae, Naemosphaera sp., Kellermania yuccagena, and Stagonospora gigantea failed to reproduce in the less acid solution. Vermicularia circinans, Pestalozzia guepini, and Ollula sp. were remarkably stimulated towards fruiting when grown in the less acid solution, while the rest generally produced a reduced number of fruit bodies.

\section{Food-concentration}

\section{Historical Considerations}

Since a review of the literature on the effect of food-concentration is not as readily available as it is in the cases of the other factors, a brief summary of the more important works is given here. No one has paid so much attention to the influence of food-concentration as Klebs. In his experiments with Hydrodictyon (9) and other algae (Io), Klebs induced the formation and discharge of zoöspores, or the development of gametes, by bringing about changes in the quantity of the available food supply of these organisms. He found that in Saprolegnia (I2) the actual stimulus for sporangium-formation consisted of the reduction of the essential food materials to a certain minimum, and that sporangium-formation became more active with each further dilution. He states that a sudden withdrawal of food is the most favorable factor in the asexual reproduction of this organism. In the summary of his own experiments as well as those of his students and other workers, Klebs (I3) cites a number of examples to substantiate his theory that "Nahrungsmangel" is a limiting factor in the reproduction of fungi. Thus, Bacillus anthracis multiplied vegetatively in a good food solution, while a lack of food induced sporulation. Didymium difforme remained in the plasmodial stage so long as it was supplied with fresh food, but when transferred to water it began to fruit. Ascoidea rubescens formed nothing

1 See page 21 for the formula of the standard solution. 
but sterile mycelium when left in plum juice, but when transferred to water, conidia developed in great abundance. Nectria cinnabarina yielded a vast quantity of conidia when its organic food was diminished, while the renovation of the liquid medium initiated a vigorous mycelial growth. Pestalozzia truncatula gave rise to a few fruit bodies on the aërial mycelium in the damp air, while on the substratum itself no pycnidia formed before the exhaustion of the food supply. According to Klebs, ascospore formation in yeasts is determined exclusively by lack of food. Guilliermond (7), summarizing the works of Klebs, Hansen, Saito, etc., concludes that ascusformation in yeasts is a much more complex phenomenon than a mere reduction of food supply, since even the actively growing hyphae are capable of forming asci; that various food substances, and such factors as oxygen, temperature, light, humidity, acidity and alkalinity, high osmotic pressure, etc., are closely associated with ascus-formation. Raciborski (19) states that concentrated solutions checked the formation of zygospores in Basidiobolus. Falck (6) observed that high concentrations of a normal nutrient medium induced zygospore-formation in Sporodinia grandis, and that more dilute solutions favored sporangium-development. Kauffman (8), working with various species of Saprolegnia, verified Klebs' findings concerning the effect of nutrition upon the growth and the reproduction of these organisms. Stevens and Hall (24) observed that a very poor medium sufficed to bring about reproduction in case of a number of fungi, while richer food substances often resulted in cessation of spore-formation. Wakefield (26) found that Schizophyllum commune and Stereum purpureum could be induced to form fruit bodies by partially or wholly removing the food from the hyphae. Raybaud (2I) states that when the mycelium of Phycomyces nitens was transferred to a high concentration of nutrient solution, after having made some growth on a medium of lower concentration, it made a good growth but formed no sporangia. When transferred to water, it gave rise to slender and well branched hyphae, but no sporangia were ever observed. This is a case in which neither a rich food nor a complete absence of food seemed to be factors in reproduction. Pieters (18) was perhaps the first investigator to determine the carrying-over properties of the mycelium. He showed that hyphae, while growing vegetatively, develop tendencies that may later affect reproduction when the fungus is subjected to the influence of changed factors. Schostakowitsch (22) found that Fumago vegans could be made to produce either sterile mycelium, or conidiophores without conidia, or sessile but mature fruiting bodies, merely by furnishing the fungus with media of different quality and quantity. Leininger (14) in his investigations on Pestalozzia palmarum found that a withdrawal of food from a growing mycelium was conducive to pycnidium-formation. Coons (4) observed that Plenodomus fuscomaculans produced no fruiting bodies when grown in solutions containing a high food-concentration, while on more dilute media, and even on filter paper plus conductivity water, it gave rise to pycnidia. 
The effect of food-concentration upon pycnidium-formation was extensively tested in the experiments described here. The experimental results were rigidly checked and counter-checked. Whenever in doubt, the work was repeated. Some of the experiments were repeated as many as six times. As stated before, the same standard solution was used exclusively. The quality always remained the same, but the concentration was changed in each case.

\section{The Effect of High Food-concentrations upon Reproduction}

As a starting-point, the fungi were grown in solutions of five different concentrations of otherwise identical composition as follows:

\footnotetext{
I. Nutrient solution of standard concentration.

II. Twice the usual concentration.

III. Four times the usual concentration.

IV. Eight times the usual concentration.

V. Sixteen times the usual concentration.
}

It should be noted that the standard solution contains only $\mathbf{1 . 5}$ percent of food matter, while the most concentrated one contains 24 percent.

The cultures, as in all cases, were made on filter-paper pads saturated with, and partially submerged in, these various solutions.

TABLE 4. The Effect of High Food-concentration upon Reproduction

\begin{tabular}{|c|c|c|c|c|c|}
\hline Organisms & $I^{*}$ & II & III & IV & V \\
\hline 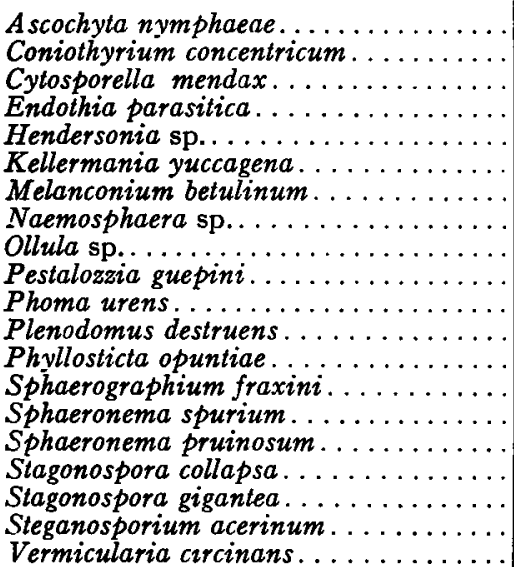 & $\begin{array}{l}60 \\
25 \\
25 \\
15 \\
20 \\
10 \\
20 \\
25 \\
10 \\
20 \\
10 \\
30 \\
40 \\
15 \\
20 \\
25 \\
20 \\
10 \\
15 \\
40\end{array}$ & $\begin{array}{l}60 \\
30 \\
50 \\
25 \\
40 \\
25 \\
30 \\
30 \\
20 \\
50 \\
20 \\
60 \\
60 \\
45 \\
40 \\
50 \\
40 \\
20 \\
20 \\
75\end{array}$ & $\begin{array}{l}70 \\
50 \\
60 \\
30 \\
45 \\
25 \\
40 \\
50 \\
50 \\
75 \\
30 \\
70 \\
60 \\
60 \\
50 \\
50 \\
70 \\
50 \\
30 \\
75\end{array}$ & $\begin{array}{l}90 \\
80 \\
85 \\
50 \\
45 \\
50 \\
60 \\
25 \\
65 \\
90 \\
50 \\
70 \\
70 \\
75 \\
75 \\
75 \\
90 \\
85 \\
50 \\
60\end{array}$ & $\begin{array}{r}0 \\
80 \\
100 \\
70 \\
50 \\
75 \\
75 \\
20 \\
65 \\
90 \\
60 \\
80 \\
60 \\
90 \\
85 \\
90 \\
100 \\
100 \\
60 \\
60\end{array}$ \\
\hline
\end{tabular}

*See explanation above of these numerals.

It is evident that the number of pycnidia generally increases with the increase in food-concentration. Only one organism, Ascochyta nymphaeae, failed to form pycnidia in the highest concentration, although it did make a very rich growth. Phyllosticta opuntiae and Vermicularia circinans did 
not respond very strongly to the highest concentration, while in the same solution Naemosphaera sp. exhibited a marked decrease in its fruiting.

In another series of experiments in which the nutrient solution used was thirty-two times the usual concentration and contained forty-eight percent of total food matter, some interesting results were obtained. Ten organisms, namely, Phoma urens, Sphaeronema pruinosum, Plenodomus destruens, Cytosporella mendax, Kellermania yuccagena, Stagonospora collapsa, Stagonospora gigantea, Endothia parasitica, Melanconium betulinum, and Pestalozzia guepini, produced a great number of fruit bodies, while the remaining organisms made a luxuriant vegetative growth but failed to form pycnidia.

\section{The Effect of a Sudden Withdrawal of Food from a Well Nourished Mycelium}

If the statement of Klebs (13), that the presence of food tends to hinder, and its sudden withdrawal from a well nourished thallus stimulates, asexual reproduction, applies not only to Phycomycetes but to Sphaeropsidales as well, then a complete withdrawal of food should promote the formation of more asexual fruit bodies than its constant presence. Consequently the following experiments were performed to test this question.

I. Check: Organisms were grown in the standard solution.

II. Check no. 2: Organisms were grown in a solution sixteen times the usual concentration.

III. The cultures were grown on pads in the usual way and in the standa rd solution until they formed a vigorous growth of hyphae, and then, just before the first fruit bodies appeared (this varying greatly with the specific organisms), were thoroughly washed in distilled sterile water and transferred to capsules which contained distilled sterile water.

IV. The filter-paper-pad cultures were grown submerged in the standard concentration to induce a more profuse mycelial growth and to retard fruiting. After a dense hyphal mass was obtained, the cultures were washed and transferred to capsules containing distilled sterile water.

V. The cultures were grown in the solution as in III, but with sixteen times the usual concentration, until they formed a vigorous growth of hyphae, and then, just before the first fruit bodies appeared, they were thoroughly washed in three changes of distilled sterile water, half an hour in each change, and were transferred to capsules containing distilled sterile water.

VI. The cultures were grown submerged in a solution sixteen times the usual concentration. After a dense hyphal mass was obtained, the cultures were washed in three changes of distilled sterile water and transferred to capsules containing distilled sterile water.

The results obtained with these experiments are given in table 5 .

A great variety of reactions can at once be noticed. Let us first compare column III, table 5, which represents the results of a sudden withdrawal of food from a normally nourished mycelium, with column I which shows the effect of the constant presence of the standard nutrient solution. Coniothyrium concentricum and Endothia parasitica are the only organisms which showed an increase in the number of fruiting bodies as the result of the withdrawal of food. Three organisms, Ollula sp., Phoma urens, and Pestalozzia guepini, remained indifferent, while the rest formed fewer pycnidia. 
TABLE 5. The Effect of Sudden Withdrawal of Food

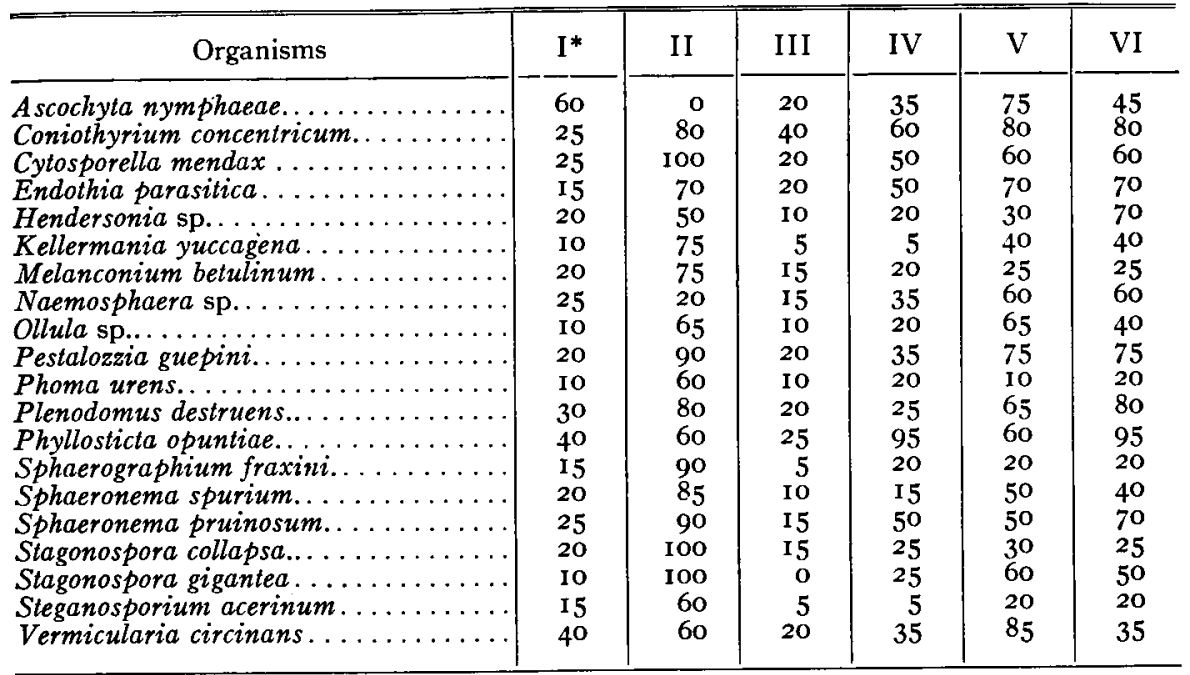

* See explanation above of these numerals.

When the cultures were grown submerged in the standard concentration (column IV), they were able to lead a longer vegetative life, had a larger quantity of food available, accumulated a higher degree of morphogenic energy, and consequently gave rise to more fruiting bodies. Ascochyta nymphaeae, Steganosporium acerinum, Kellermania yuccagena, Plenodomus destruens, Sphaeronema spurium, and Vermicularia circinans showed a slight reduction in the number of their fruit bodies; Hendersonia sp. and Melanconium betulinum were unaffected, while the remaining organisms were favorably stimulated.

Passing now to the highest concentration, let us compare column II which shows the effect of the constant presence of much food throughout the life cycle of these fungi, with column $\mathrm{V}$ in which are summarized the results obtained by the sudden withdrawal of food from an actively growing mycelium. Ascochyta nymphaeae, Naemosphaera sp., and Vermicularia circinans are the only organisms which formed more fruit bodies when the food was withdrawn than when it was constantly present. However, it should not be forgotten that the first-named organism does not form pycnidia at all when left growing in the high concentration, and the remaining two do not attain their maximum reproduction when the concentration is as high as this. Coniothyrium concentricum, Endothia parasitica, Ollula sp., and Phyllosticta opuntiae remained unaffected, while all the other organisms, thirteen in number, formed a reduced number of fruit bodies as a result of the withdrawal of the rich food from the mycelium.

When the cultures were grown submerged in the high concentration and then washed and transferred to distilled water, only five organisms, namely, 
Hendersonia sp., Phoma urens, Plenodomus destruens, Phyllosticta opuntiae, and Sphaeronema pruinosum, exhibited an increase in their fruit bodies. Ascochyta nymphaeae, Ollula sp., Sphaeronema spurium, Stagonospora collapsa, Stagonospora gigantea, and Vermicularia circinans had a decreased reproduction, while the remaining nine organisms were indifferent in their reactions.

Cytosporella mendax showed some interesting modifications: after making a good vegetative growth, and after being washed and transferred to distilled water, it failed to form stromata, and most of the fruiting appeared as naked spore masses, the pycnidial walls of which were entirely eliminated. Endothia parasitica under similar treatment also formed no stromata, and pycnidia likewise appeared singly.

Table 5 shows that a number of organisms produced very few fruit bodies when they were transferred from either the high or the low concentration of the nutrient solution directly to distilled water. In order to find if the mycelium still retained its normal vitality in spite of its inability to reproduce well, the cultures were retransferred from distilled water to the nutrient solution of standard concentration. Shortly after the transfer, a very large number of fruit bodies appeared, in some cases covering every available space of the substratum with pycnidia. $A p$ parently a transfer to distilled water initiates a great number of the microscopic beginnings of pycnidial stages, but few of these mature unless sufficient food is present.

An experiment was set up to find whether there was a direct parallel between the quantity of mycelium and the amount of pycnidia formed. Cultures were started in the standard solution. After a fair hyphal growth was obtained and before the first fruit bodies appeared, the cultures were transferred to capsules each of which contained $20 \mathrm{cc}$. of the standard solution. The organisms were allowed to grow submerged in this solution. Then the cultures were divided into three groups: the first was allowed to grow submerged for two days; the second, for four days; and the third, for eight days. At the end of these periods of growth the cultures were washed and transferred to distilled sterile water. In every case the quantity of hyphae was proportionally increased with the length of the period in the submerged condition. In only four organisms could an appreciable proportional difference be seen between the quantity of the mycelium and the amount of fruit bodies. Sphaerographium fraxini, Sphaeronema pruinosum, and Stagonospora gigantea formed a larger number of pycnidia as the length of the vegetative period was increased; Phyllosticta opuntiae exhibited a decrease in its number of pycnidia after it was allowed to grow submerged for eight days and then transferred to distilled water; however, very good development of pycnidia was obtained when the submerged growth was reduced from eight to four days. In the case of the remaining sixteen organisms the number of fruit bodies was the same in a given area, regardless of the quantity of mycelium. 


\section{The Effect of Gradual Changes of Concentration}

We have seen that a sudden withdrawal of food induces three types of reactions depending on the fungi worked with: some are stimulated to better pycnidial production, others remain indifferent, while still others exhibit a more or less decided decrease in the quantity of fruiting bodies. The next logical step in these investigations was to test, first, the effect of a gradual withdrawal of food until a known minimum is reached, and second, to find if a gradual increase of concentration to a known maximum and then a sudden transfer to a known minimum would induce reactions similar to those recorded in column $\mathrm{V}$ of table 5. The five concentrations of the nutrient solutions, as previously described, were used in the following experiments. cycle.

Check: The organisms were grown in the standard solutions throughout their life

I. The organisms were grown on filter-paper pads and kept in the standard solution; after a good hyphal growth had been obtained and just before the first fruiting bodies had appeared, the cultures were washed in distilled sterile water and transferred to another series of solutions of twice the usual concentration. Twenty-four hours later the cultures were washed and transferred to solutions of four times the usual concentration, and the process was continued in this way until solutions of sixteen times the usual concentration were reached; in the latter solutions the cultures were allowed to remain for a day, after which they were washed and transferred to solutions of the standard concentration.

II. The reverse of the above-described treatment: The organisms in this case were grown on filter-paper pads kept in solutions of standard concentration until a good hyphal growth was obtained: then they were washed and transferred directly to solutions of sixteen times the usual concentration. At regular intervals of twenty-four hours they were gradually passed down to the less and less concentrated solutions until the standard solution was reached.

III. In this series, after the cultures had made a good vegetative growth in the standard solutions, they were washed and transferred to a fresh lot of the standard solution. This process was repeated for five days at twenty-four hour intervals, when the cultures were left undisturbed.

IV. Same as in III, except that washing operations before each transfer were eliminated.

The last two experiments eiiminate osmotic pressure as a possible factor, and do away with the objection that the process of washing the cultures free from the accumulated waste matter may be the real cause of the results obtained.

In most cases it makes little or no difference whether a normally grown mycelium is gradually transferred from a low to a higher concentration, or whether it is transferred directly to the high concentration and is gradually carried down to the lower one. Plenodomus destruens, Cytosporella mendax, Naemosphaera sp., Kellermania yuccagena, Stagonospora gigantea, Hendersonia sp., Steganosporium acerinum, Sphaerographium fraxini, Endothia parasitica, Melanconium betulinum, and Pestalozzia guepini showed an increased pycnidium-production when transferred from lower to higher 
TABLE 6. The Effect of Gradual Increase or Decrease of Food-concentration

\begin{tabular}{|c|c|c|c|c|c|}
\hline Organisms & Check & $I^{*}$ & II & III & IV \\
\hline 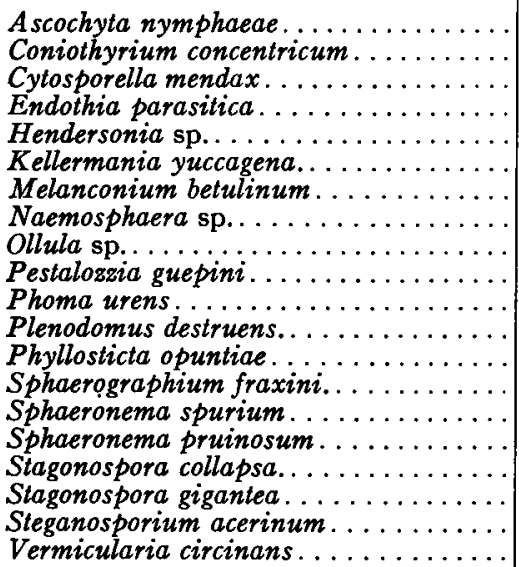 & $\begin{array}{l}60 \\
25 \\
25 \\
15 \\
20 \\
10 \\
20 \\
25 \\
10 \\
20 \\
10 \\
30 \\
40 \\
10 \\
20 \\
25 \\
20 \\
10 \\
15 \\
40\end{array}$ & $\begin{array}{r}65 \\
100 \\
85 \\
75 \\
90 \\
20 \\
60 \\
60 \\
50 \\
100 \\
50 \\
90 \\
50 \\
40 \\
80 \\
90 \\
85 \\
90 \\
100 \\
100\end{array}$ & $\begin{array}{r}65 \\
100 \\
60 \\
70 \\
80 \\
10 \\
50 \\
50 \\
50 \\
90 \\
50 \\
80 \\
70 \\
80 \\
50 \\
90 \\
85 \\
80 \\
85 \\
100\end{array}$ & $\begin{array}{r}20 \\
70 \\
60 \\
50 \\
35 \\
5 \\
40 \\
60 \\
30 \\
65 \\
50 \\
80 \\
80 \\
15 \\
30 \\
40 \\
75 \\
45 \\
20 \\
100\end{array}$ & $\begin{array}{l}70 \\
70 \\
70 \\
40 \\
30 \\
30 \\
40 \\
60 \\
40 \\
75 \\
50 \\
90 \\
60 \\
15 \\
30 \\
40 \\
75 \\
60 \\
20 \\
100\end{array}$ \\
\hline
\end{tabular}

* See explanation above of these numerals.

concentrations. In the case of Phyllosticta opuntiae; pycnidium-formation was reduced and the remaining organisms were indifferent. When compared with the checks, however, a general and sharp increase in pycnidiumproduction was noticeable for all species.

A comparison of the fourth column of table 6 with the second column shows that in the cases of some organisms it makes no difference whether the concentration of the solution is gradually increased, or whether it is kept at the same low concentration, provided that a fresh solution is used once a day for five consecutive days. Phyllosticta opuntiae formed more fruit bodies when it was given a fresh solution of low concentration for five days than it did when higher concentrations were used. Naemosphaera sp., Phoma urens, and Vermicularia circinans were indifferent, while the fruiting was more or less reduced in the remaining organisms.

Phyllosticta opuntiae and Naemosphaera sp. formed more pycnidia when they were washed and transferred to a fresh supply of the standard concentration for five consecutive days than when transferred to the standard medium gradually from the solution of sixteen times the usual concentration. Cytosporella mendax, Phoma urens, Plenodomus destruens, and Vermicularia circinans remained indifferent, while the remaining organisms gave rise to fewer fruit bodies.

The elimination of washing operations before each transfer not only failed to be harmful, but it became decidedly beneficial for some organisms, as can be seen in the last column of table 6. Ascochyta nymphaeae, Cytosporella mendax, Kellermania yuccagena, Ollula sp., Pestalozzia guepini. Plenodomus destruens, and Stagonospora gigantea showed an increased 
pycnidium-production. Only Endothia parasitica, Hendersonia sp., and Phyllosticta opuntiae showed a reduced quantity of pycnidia, while the remaining species were indifferent.

It can be seen that six organisms, namely, Hendersonia sp., Steganosporium acerinum, Melanconium betulinum, Sphaerographium fraxini, Sphaeronema spurium, and Sphaeronema pruinosum, failed to respond very vigorously when they were carried through five changes of the standard solution. It was concluded that a longer growing period might be responsible for this behavior, and that, if the transfer were made at longer intervals, the organisms might be able to utilize the fresh supply of the nutrient solution to better advantage. Consequently, in an additional series, the first transfer was made after the appearance of the fruit bodies. Shortly thereafter a vigorous reproduction took place, so that, with the exception of Sphaerographium fraxini, all other organisms showed a remarkable gain in the quantity of pycnidia produced.

It should be stated here that washing operations caused an abundant development of hyphomycetous conidia in cultures of Ascochyta nymphaeae. It seems that this organism tends to behave in this way regularly when washed in distilled water. When the cultures of this species were gradually transferred from high to low or from low to high concentrations, an abnormally large quantity of hyphomycetous conidia appeared and covered the substratum with a solid mass of salmon-colored spores; later, pycnidia appeared and covered this spore mass. Cytosporella mendax showed a similar, but not always so prominent, tendency.

That a fresh supply of food of the standard concentration, supplied at regular intervals to the growing organisms, brings about results similar to those which were obtained with the higher concentrations of the same solution, becomes apparent by comparing the first column of table 6 with the last two columns. With the exception of Sphaerographium fraxini, which remained indifferent, and which has given erratic results in many of the experiments, all the organisms showed an increase in the number of pycnidia. Kellermania yuccagena showed a reduced pycnidial production when the cultures were washed before being transferred to a fresh solution. This has been the case with this particular organism every time that it was washed in distilled water. However, it never has been a very vigorous and free pycnidium-former, at least not in the medium used. Although $A$ scochyta nymphaeae showed a decrease in number of pycnidia as a result of washing the cultures in distilled water, it gave rise, nevertheiess, to a much larger quantity of hyphomycetous conidia and thus made up for the deficiency in the number of pycnidia.

The Effect of Sudden Increase of Concentration on Normally Grown Mycelium

After testing the effects of sudden withdrawal of food and of gradual increase or decrease in food-concentration, it was decided to determine the 
effect of a sudden increase in food-concentration. Consequently the following experiment was set up.

I. Check: The organisms were grown on filter-paper pads kept in solutions of sixteen times the standard concentration.

II. After the organisms had made a good growth on filter-paper pads kept in the standard concentration, and before the first visible fruit bodies had appeared, they were washed and transferred to solutions of sixteen times the standard concentration.

TABLE 7. Effect of a Sudden Increase of Concentration upon a Normally Grown Mycelium

\begin{tabular}{|c|c|c|}
\hline Organisms & I. Check & $\begin{array}{l}\text { II. Transferred to High } \\
\text { Concentration }\end{array}$ \\
\hline Ascochyta nympheae .............. & $\mathbf{o}$ & 100 \\
\hline Coniothyrium concentricum . . . . . . . . . & 80 & 90 \\
\hline Cytosporella mendax $\ldots \ldots \ldots \ldots \ldots \ldots \ldots \ldots$ & 100 & 100 \\
\hline Endothia parasitica $\ldots \ldots \ldots \ldots \ldots \ldots \ldots$ & 70 & 50 \\
\hline 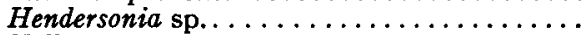 & 50 & IOO \\
\hline Kellermanua yuccagena. . . . . . . . . . . . & 75 & 75 \\
\hline Melanconium betulinum............... & 75 & 100 \\
\hline Naemosphaera sp................ & 20 & 10 \\
\hline 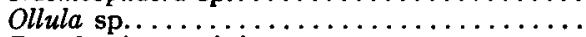 & 65 & 25 \\
\hline 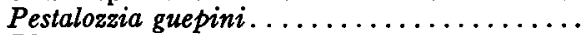 & 90 & 100 \\
\hline Phoma urens . . . . . . . . . . . . . . & 60 & 85 \\
\hline Plenodomus destruens. . . . . . . . . . . . . & 80 & IOO \\
\hline Phyllosticta opuntiae. . . . . . . . . . . . & 60 & 40 \\
\hline Sph̆aerographium fraxini.............. & 90 & 100 \\
\hline Sphaeronema spurium.............. & 85 & 100 \\
\hline Sphaeronema pruinosum.............. & 90 & IOO \\
\hline Stagonospora collapsa............... & IOO & 100 \\
\hline Stagonospora gigantea . . . . . . . . . . . & 100 & IOO \\
\hline Steganosporium acerinum $\ldots \ldots \ldots \ldots \ldots$ & 60 & 100 \\
\hline Vermicularia circinans................ & 60 & 85 \\
\hline
\end{tabular}

In the cases of Endothia parasitica, Naemosphaera sp., Ollula sp., and Phyllosticta opuntiae, the fruiting was reduced as a result of sudden transfer to a food of high concentration. Kellermania yuccagena remained indifferent, while all the other organisms exhibited a remarkable increase in the quantity of pycnidia. Ascochyta nymphaeae, which failed to form any pycnidia when kept constantly in solutions of high concentration, developed a large number of fruit bodies when transferred to such a solution in the manner described. It might, perhaps, be supposed that the filter-paper pad, when being washed in distilled water, would absorb enough water to dilute the nutrient solution to which it was transferred. Further experiments showed, however, that this was not a factor in the case. For when the cultures, after being washed in distilled water, were allowed to evaporate to complete dryness and then transferred directly to solutions of sixteen times the standard concentration, they produced pycnidia just as abundantly. The small amount of water that might be carried into the new solution by the wet filter paper soon evaporates, and the culture method is such that the fungus utilizes all or most of the nutrient matter by the time it completes its life cycle. Stagonospora collapsa, which normally formed pycnidia singly, gave rise to a number of large, well developed stromata when it was transferred to solutions of high food concentration. 


\section{The Effect of Food of the Standard Concentration upon Mycelium Richly Fed and then Allowed to Starve}

Klebs (10, I2, 13) states that the sudden removal of food stimulated asexual reproduction in a number of organisms with which he and his students experimented. Kauffman (8), Pieters (I8), and others have verified Klebs' findings in Saprolegnias and other organisms. Yet we have seen (p. 3I) that, in the cases of a large number of organisms worked with in the present investigation, a sudden withdrawal of food from a well nourished mycelium failed to induce the formation of pycnidia to the same extent as when food was constantly present. It was therefore assumed that these organisms require a longer period for the production of these bodies and need a longer-continued food supply: and that, although the sudden removal of food did not stimulate the fungus sufficiently to initiate and mature a large number of pycnidia, it might, nevertheless, be effective to the extent that it might initiate the beginnings of a larger number of fruit bodies and that these might have remained undeveloped because of the absence of food. If this hypothesis is correct, then the mycelium, after a period of starvation, should give rise to a large number of pycnidia when transferred to the standard solution. Accordingly, the following experiments were set up.

I. Check: Cultures were made and kept in solutions of sixteen times the usual concentration.

II. Check no. 2: Cultures were made and kept in solutions of sixteen times the usual concentration until a good hyphal growth was obtained and before the first fruit bodies appeared; then they were washed in several changes of distilled water and transferred to distilled water.

III. Cultures were made and kept in solutions of sixteen times the usual concentration until a good hyphal growth was obtained and before the first fruit bodies appeared; then they were washed thoroughly in three changes of water, one half hour in each change, and transferred to the standard solution.

IV. Same as experiment III, except that instead of transferring the cultures directly to the ordinary nutrient solution they were first kept in distilled sterile water until they gave rise to as many fruit bodies as possible; then they were transferred to the standard solution.

Table 8 gives the results.

The difference between the third and the fourth columns of table 8 is so slight as to be disregarded altogether except in case of the figures for Phyllosticta opuntiae. The optimum food-concentration for this organism seems to be very low, so that even the standard solution, when immediately furnished to the richly nourished mycelium, is sufficient to disturb the equilibrium between vegetative growth and reproduction at the expense of the pycnidia. A comparison between the last two columns and the second column shows that a period of starvation initiates a larger quantity of fruiting bodies which can develop and reach maturity if furnished with a smaller amount of food. Hendersonia sp., Steganosporium acerinum, 
TABLE 8. The Effect of a Weak Food Solution Upon a Mycelium After It Was Richly Fed and Then Starved

\begin{tabular}{|c|c|c|c|c|}
\hline Organisms & $I^{*}$ & II & III & IV \\
\hline 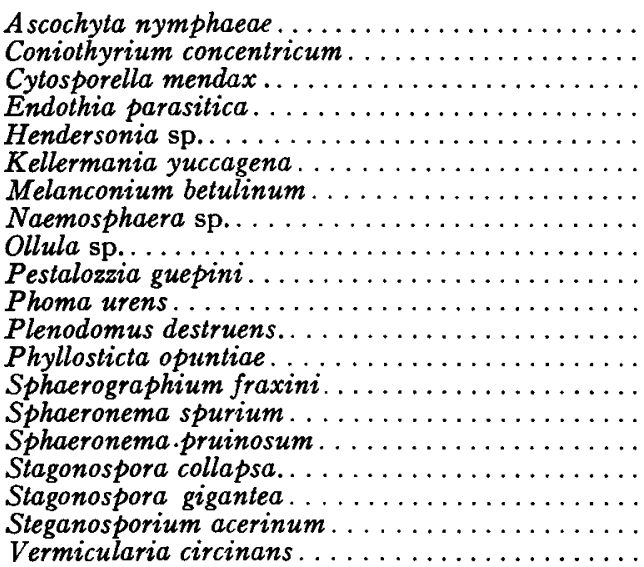 & $\begin{array}{r}0 \\
80 \\
100 \\
70 \\
50 \\
75 \\
75 \\
20 \\
65 \\
90 \\
60 \\
80 \\
60 \\
90 \\
85 \\
90 \\
100 \\
100 \\
60 \\
60\end{array}$ & $\begin{array}{l}70 \\
80 \\
60 \\
70 \\
30 \\
40 \\
25 \\
60 \\
65 \\
75 \\
10 \\
65 \\
60 \\
20 \\
50 \\
50 \\
30 \\
60 \\
20 \\
85\end{array}$ & $\begin{array}{l}70 \\
80 \\
60 \\
65 \\
40 \\
60 \\
40 \\
75 \\
65 \\
75 \\
45 \\
80 \\
40 \\
35 \\
55 \\
50 \\
70 \\
75 \\
45 \\
85\end{array}$ & $\begin{array}{l}70 \\
80 \\
60 \\
70 \\
40 \\
60 \\
40 \\
75 \\
65 \\
80 \\
50 \\
80 \\
85 \\
35 \\
60 \\
50 \\
70 \\
75 \\
45 \\
85\end{array}$ \\
\hline
\end{tabular}

* See explanation above of these numerals.

Kellermania yuccagena, Melanconium betulinum, Naemosphaera sp., Phoma urens, Pestalozzia guepini, Plenodomus destruens, Phyllosticta opuntiae, Sphaerographium fraxini, Sphaeronema spurium, Stagonospora collapsa, and Stagonospora gigantea were stimulated and produced more pycnidia, while the remaining species were indifferent. It appears that the dilute nutrient solution may not only act like distilled water in initiating a larger number of initial pycnidia, but that it may also furnish them with enough food for their maturing.

\section{The Carrying-over Effect of the Mycelium}

Many of the experiments already described have shown that the mycelium may acquire a certain tendency when subjected to one set of environmental factors and may manifest no sign of this tendency unless it is acted upon by a changed environment. Klebs (I2, I3) recognized similar phenomena, and Pieters (I8) demonstrated them more definitely. In order to demonstrate this carrying-over effect of the mycelium more strikingly, it was necessary to employ a different nutrient solution from the one used throughout these experiments; a solution that would prove uniformly hostile to pycnidium-formation in all the organisms. The following formula was found to give the most satisfactory result in this respect: ammonium nitrate I gram, dihydrogen potassium phosphate 0.5 gram, magnesium sulphate 0.25 gram, cane sugar 5 grams, and distilled water $100 \mathrm{cc}$. For the sake of convenience, this will be referred to as solution $B$, while the standard 
one used throughout the work will be termed solution $A$. The following experiments were set up.

I. Check no. I: Organisms were grown in solution $A$.

II. Check no. 2: Organisms were grown in solution $B$.

III. Check no. 3: Organisms were grown in solution $B$ until a good hyphal growth was obtained; then they were washed in distilled sterile water and transferred to a fresh supply of solution $B$.

IV. Organisms were grown in solution $B$ until a good hyphal growth was obtained; then they were thoroughly washed in distilled sterile water and transferred to capsules containing distilled sterile water.

V. Organisms were grown in solution $B$ until a good hyphal growth was obtained; then they were thoroughly washed and transferred to solution $A$.

VI. Organisms were grown in solution $A$ until a good hyphal growth was made; then they were washed and transferred to solution $B$.

TABLE 9. The Carrying-over Effect of the Mycelium

\begin{tabular}{|c|c|c|c|c|c|c|}
\hline Organisms & $I^{*}$ & II & III & IV & V & V I \\
\hline 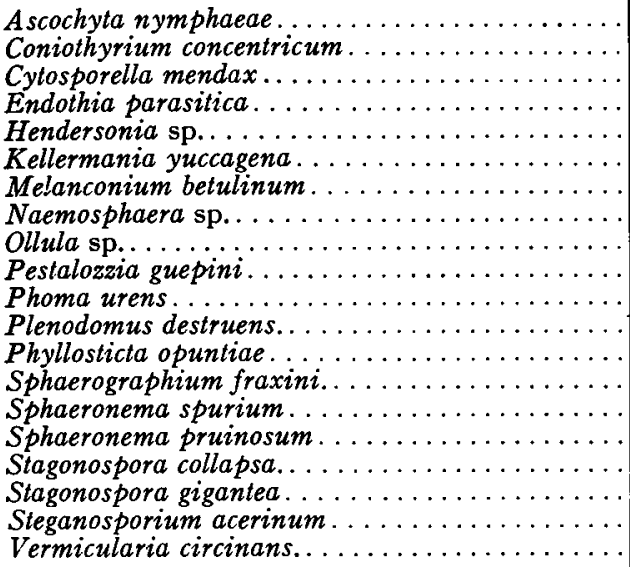 & $\begin{array}{l}60 \\
25 \\
25 \\
15 \\
20 \\
10 \\
20 \\
25 \\
10 \\
20 \\
10 \\
30 \\
40 \\
15 \\
20 \\
25 \\
20 \\
10 \\
15 \\
40\end{array}$ & $\begin{array}{r}\mathbf{0} \\
\mathbf{0} \\
\mathbf{0} \\
\mathbf{5} \\
\mathbf{0} \\
\mathbf{0} \\
\mathbf{0} \\
\mathbf{0} \\
\mathbf{0} \\
\mathbf{0} \\
\mathbf{0} \\
5 \\
\mathbf{0} \\
\mathbf{0} \\
\mathbf{5} \\
\mathbf{0} \\
\mathbf{1 0 0} \\
\mathbf{5} \\
\mathbf{0} \\
\mathbf{7 0}\end{array}$ & $\begin{array}{r}\text { O } \\
0 \\
0 \\
5 \\
0 \\
0 \\
0 \\
0 \\
0 \\
0 \\
0 \\
5 \\
0 \\
0 \\
5 \\
0 \\
100 \\
5 \\
0 \\
85\end{array}$ & $\begin{array}{r}5 \\
0 \\
0 \\
5 \\
0 \\
0 \\
0 \\
0 \\
0 \\
20 \\
5 \\
10 \\
0 \\
0 \\
0 \\
0 \\
25 \\
5 \\
0 \\
40\end{array}$ & $\begin{array}{r}25 \\
80 \\
25 \\
35 \\
60 \\
10 \\
20 \\
40 \\
15 \\
80 \\
20 \\
20 \\
30 \\
35 \\
40 \\
20 \\
100 \\
40 \\
20 \\
70\end{array}$ & $\begin{array}{r}5 \\
30 \\
5 \\
5 \\
15 \\
5 \\
0 \\
0 \\
10 \\
20 \\
0 \\
60 \\
0 \\
0 \\
25 \\
0 \\
100 \\
5 \\
5 \\
100\end{array}$ \\
\hline
\end{tabular}

Table 9 shows that solution $A$ induced the formation of fruit bodies in all of the twenty organisms, while solution $B$ inhibited it in fourteen. Four of the remaining six fungi developed but few pycnidia. while Stagonospora collapsa and Vermicularia circinans gave rise to a much larger quantity of fruit bodies than they did when grown in solution $A$. Column III, which represents the results obtained when the cultures were transferred from solution $B$ to a fresh supply of the same solution, is very much like column II, except that Vermicularia circinans formed more fruit bodies as a result of the transfer. When transferred from solution $B$ to distilled water, Pestalozzia guepini and Phoma urens developed pycnidia, the former organism giving rise to as many of them as it did when grown in solution $A$. The most

* See explanation above of these numerals. 
remarkable results, however, are to be obsrved in column V. After a transfer from solution $B$ to solution $A$, only four organisms, namely, Ascochyta nymphaeae, Plenodomus destruens, Phyllosticta opuntiae, and Sphaeronema pruinosum, exhibited a reduced amount of fruiting. Three others, Cytosporella mendax, Kellermania yuccagena, and Melanconium betulinum, were unaffected by the change, while all the remaining organisms were stimulated so as to produce more pycnidia. If we now turn our attention to the last column, where the order was reversed-that is, the organisms were first grown in solution $A$ and then transferred to solution $B$--we see that Plenodomus destruens and Vermicularia circinans gave rise to a still better pycnidial production. However, Melanconium betulinum, Naemosphaera sp., Phoma urens, Sphaerographium fraxini, and Sphaeronema pruinosum failed to fruit, Stagonospora collapsa was unaffected, while the remaining organisms showed a reduction in quantity of fruit bodies.

\section{Discussion}

Light. It has been seen (table $\mathrm{I}$ ) that light is an important factor in the fruiting of a number of organisms. The intensity of action of this stimulus, however, varies with the specific nature of each fungus, or with the altered combinations of other stimuli. Thus, although Sphaerographium fraxini formed no pycnidia in the dark and at room temperature, it did give rise to a few fruit bodies at a temperature of $30^{\circ} \mathrm{C}$. Other organisms, which were not able to develop more than very few pycnidia in the dark and at room temperature, or in the ordinary nutrient solution, gave rise to a greater abundance of fruit bodies when the temperature was raised, or when the concentration of the medium was increased, even though light was excluded. It may be said (Coons, 4, p. 76I) that the direct result of the presence of light is oxidation; that, since a higher temperature or a richer food tends to bring about a higher oxidation and a more rapid metabolism, the increased reproduction would naturally be traced to the effect of oxidation. But it should not be forgotten that Hendersonia sp. failed to give rise to a single fruit body either when growing in a higher concentration of food, or at a higher temperature so long as light was excluded. Perhaps a higher oxidation requirement, coupled, on the one hand, with a possible inhibiting action of the higher temperature, and, on the other hand, with the less favorable influence of a higher food-concentration, altered the balance between the mycelium and the fruit bodies in favor of hyphal development and culminated in the sterility of the cultures. While this explanation sounds plausible, we have the experiments of Lendner (I5) in which a mere addition of agar agar to a nutrient solution supplemented the white light so that Mucor flavidus was able to form sporangia in spite of the absence of white light.

Temperature. As has already been stated, a higher temperature is not only capable of inducing the development of more pycnidia, but in 
some cases it even replaces, partially or wholly, the effect of light (table I, column III). The majority of the organisms either failed to fruit at $8^{\circ} \mathrm{C}$., or pycnidium-formation was materially reduced. The eight organisms which formed no pycnidia at this low temperature and in the dark gave rise, however, to a normal number of fruit bodies when they were transferred to the light but were still kept at the same temperature. The low temperature, provided that light is not excluded, merely delays fruiting. A slow oxidation and a slow metabolism seem to be responsible for this delay. But when light is excluded, oxidation falls below the minimum requirement for pycnidium-formation, but not below that for growth; consequently the organisms lead a sterile life until they are transferred to light.

Oxygen Supply. The works of Raulin (20), Schostakowitsch (22), Klebs (IO, II), Coons (4), etc., as well as the experiments outlined in this paper (table 2), show that a lack of oxygen supply is generally an inhibiting factor in the growth and reproduction of a large number of fungi. Only six organisms out of the twenty worked with remained unaffected by a reduced oxygen supply. Perhaps a narrower oxygen requirement on the one hand, and a much shorter life cycle on the other, were the chief factors responsible for the behavior of these six organisms.

Adsorption. Adsorption of nutrient salts appears not to be a factor in the growth and the reproduction of the organisms so long as there is a good supply of moisture (table 3 ). The adsorption of water molecules, however, is an important factor. We have seen that the organisms stopped growth when the moisture was decreased, and when the fibers of filter paper, the molecules of the colloid (agar agar), or the particles of powdered glass held the water molecules so firmly that the hyphae were powerless to utilize them. In a former paper (16) the writer demonstrated that Fusarium annuum, when grown on different types of soil, was unable to make further growth after the moisture content of a very fine sand substratum was reduced to 5.6 percent, while in clay-soil substrata growth ceased in spite of the fact that the soil still contained 10.5 percent of capillary moisture. The smaller particles of clay soil with their larger adsorbing surfaces were evidently responsible for this result. It follows that there is a very strong affinity between the water molecules and the non-living, non-assimilative particles. It is also probable that in culture media there is a certain amount of adsorption of salts, but not in large enough quantities to have an effect on the development of the organisms. Filter-paper fibers have an immense adsorbing area, and agar agar molecules are known to have such a powerful adsorbing capacity that even one percent agar agar can adsorb and solidify under certain conditions ninety-nine percent of water; yet fungi have no difficulty in obtaining their nourishment in spite of the presence of these adsorbing agents.

Transpiration. Not all of the organisms were affected by a lack of free transpiration. We have seen (table 3 ) that the fungi in their relation to 
this factor can be divided into five groups: first, those which must be surrounded in part by air in order to be able to form pycnidia; second, those which form fruit bodies either submerged or on top of the nutrient solution, but more abundantly when surrounded by air; third, those which give rise to more pycnidia when submerged than they do on the surface of the solution; fourth, those which reproduce with equal ease under any of these conditions: and fifth, those organisms which are capable of forming pycnidia when submerged, but which must rise above the water in order to mature their spores. Oxygen requirements and transpiration are largely responsible for these variations. Reproduction under water, however, is affected not only by chemical, but by physical factors as well. This matter is discussed more thoroughly in the following paragraph.

Solidity of Substratum. An examination of the first column of table 3 leads one to wonder why so many organisms failed to do well in liquid media. Since experiments outlined and tabulated in the same table have indicated that adsorption is not a factor so long as there is an ample supply of available moisture, and since tables $4,5,6$, and 7 show that higher food-concentrations favor rather than hinder reproduction, it can not be asserted that the presence of agar agar or filter paper in the nutrient solution tends to adsorb the molecules of food substance, and so leaves a poorer medium which discourages growth and stimulates pycnidium-formation. A reduced air supply in a liquid medium coupled with a total lack of transpiration on the one hand, and the absence of adequate supporters, on the other hand, to keep buoyant the hyphae of such organisms as always tend to form a very compact and heavy mycelium, may be largely responsible for the reduced production of pycnidia. Those fungi which naturally form a light and floccose mycelium will find sufficient support in the solution to keep them floating and to induce the development of good aërial hyphae which, because of a free transpiration, are not hindered from giving rise to fruiting bodies. Such slow-growing organisms as Sphaeronema spurium and Sphaerographium fraxini, which produce a very heavy and compact mycelial mass, sink into the solution and grow submerged, and are thus unable to form pycnidia. Solid media offer a more available air supply and allow a freer oxidation and respiration as well as a better support for the free ramification of hyphal threads. Negative adsorption whereby the water molecules are adsorbed instead of the salts, thus bringing about a more concentrated solution, may also be a factor in this case.

Food-concentration. Almost all the important investigations concerning the influence of food-concentration have been made with the Phycomycetes. Since there is a wide morphological dissimilarity between the Phycomycetes and the Sphaeropsidales, might it not be likely that the physiological differences may prove to be just as distinct? The Phycomycetes are coenocytic, the entire mycelium being one continuous tube system which enables the protoplasm to respond or migrate from one end of the mycelium 
to the other under the stimuli which govern reproduction (Conidiobolus utriculosus; Brefeld, 3). DeVries (5) and others have observed the movement of the protoplasm in Phycomyces into the newly forming sporangia. Arthur (2) examined protoplasmic movements in a number of Mucoraceae and observed that hyphae, microsomes, food bodies, nuclei, and vacuoles participate. He states that the flow of protoplasm is most commonly towards the free aërial parts and the fast growing tips where a rapid use of food removes obstacles from the advancing column of protoplasm. This movement was seen to come to a halt whenever a cross wall appeared. We can see, therefore, that a heavy demand made by the sporangiophores upon the rest of the mycelium for a large quantity of food can be speedily met by the migration of the protoplasm into the sporangium-initials.

It has been shown that the constant presence of a specific type of rich food breaks up the balance between vegetative growth and asexual reproduction, stimulating the former and suppressing the latter; hence the sterility of certain species of Saprolegnia when grown in pea broth (Kauffman, 8; Pieters, I8). On the other hand, sexual reproduction demands comparatively more food than sporangium-formation, and therefore a total absence of food hinders the development of oögonia. Klebs $(12,13)$ states that the minimum concentration of the most important food materials is higher for oöspore formation than it is for zoöspore development.

Now, if we consider the Sphaeropsidales, we find that the septate nature of the hyphae prevents an appreciable migration of the protoplasm from cell to cell and hinders an adequate translocation of food into the pycnidiuminitials. The osmotic transference is presumably much slower than in the Phycomycetes. This is especially true in the case of those organisms which form stromata, thick pycnidial walls, and large spores rich in reserve food. Consequently, most of the Sphaeropsidales, when allowed to starve, even though they have been grown in media rich in food, tend to form fewer fruit bodies than they do when food is constantly present. Phyllosticta opuntiae and similar organisms which form very small pycnidia and spores, the latter poor in reserve food, naturally do not require a very rich food supply, and form fruit bodies best when this supply is withdrawn from the actively growing mycelium.

Higher concentrations of the nutrient solution induce the formation of more mycelium and more pycnidia until a given maximum is reached. In other words, mycelial growth and reproduction are parallel within a very wide margin. Coons (4) states that Plenodomus fuscomaculans when grown in rich nutrient solutions forms its pycnidia not upon the substratum itself, but on the aërial strands, and he explains this by saying that a dense mycelial mat formed over the agar effectively walls off the new food supply, and that "with the increase in concentration in the medium below and the drying of the threads, the diffusion of food stuffs to the aërial parts is interfered with." The lack of food thus brought about is said to become responsible for the 
appearance of the pycnidia on the aërial strands of his fungus. But it can not be assumed that in the experiments shown in table 4 any "walling off" effect could be operative. In no case were the pycnidia formed on wefts of aërial mycelium, but they were directly seated upon or imbedded in the filter-paper pads which were saturated with, and partially submerged in, the nutrient solution; thus, young or old fruit bodies were always in direct contact with the food. Ascochyta nymphaeae formed a great abundance of aërial hyphae in the richest nutrient solution, but not a single pycnidium. Similarly, on a nutrient medium which contained forty-eight percent of available food, nine other organisms made an unusually rich aërial growth but gave rise to no fruit bodies.

Osmotic pressure can not be a factor in the fruiting of the organisms worked with in these experiments. The last column of table 6 shows that it makes little or no difference in these organisms whether their demand for more food is supplied all at once in the form of a high concentration of nutrient solution or whether the food is supplied bit by bit in the form of a fresh supply offered as a weak nutrient medium (table 6, columns III and IV). In the first case there is a high osmotic pressure, while in the second case this pressure, so far as the solution itself is concerned, remains constant and very weak; yet pycnidium-production is increased most remarkably. In both cases it is the same factor that functions, namely, the large supply of food. Apparently the quantity makes up for the concentration. But, it may be asked, how is it that five changes of a solution which is so dilute in its food value are as effective as a solution sixteen times the usual concentration? At most the organisms have access to a total of food which is only five times as strong as the standard concentration, yet the effect is much greater for the production of pycnidia. It is not probable that fungi exhaust all available food supply when grown in a nutrient solution, because a cessation of growth does not necessarily mean a lack of food, but may signify that the food-absorbing capacity of the mycelium has reached its limit so far as a given solution is concerned. When grown in a nutrient solution of high concentration, these organisms sooner or later reach the limit of their absorbing capacity, and therefore utilize only a part of the available food. Probably the five transfers into a fresh medium of low concentration furnished as much food as the solution of high food-concentration. This, naturally, led to a better reproducing capacity in the majority of the fungi. It should also be remembered that the cultures were first transferred to a new solution after they had made a good growth, and had, therefore, in addition to a well developed vigor and distinct physiological changes towards pycnidium-production, a very extensive absorbing system capable of taking in and assimilating within a very short time large quantities of food from the fresh supply of nutrient solution. During the five consecutive transfers the constantly growing mycelium developed a still larger absorbing surface and stored away much food. Thus there was a constant ac- 
cumulation of nutrient substances in the protoplasm; naturally this provided the basis for a high efficiency in the production of pycnidia, whereas those cultures which were kept constantly in the same supply of dilute food soon exhausted their absorbing capacity and did not have sufficient food for an abundant reproduction. But not all the organisms behaved similarly. Perhaps some of them could not get the maximum amount of necessary food from such a large quantity of dilute nutrient solution because of an innate slow growth and absorption. This hypothesis is strengthened by the fact that when these organisms were transferred, after they had ceased their growth and pycnidium-formation in the standard concentration, to a fresh supply of the same solution, the number of pycnidia increased very remarkably. An organism which has a short life cycle derives the most benefit when it is transferred to five changes of dilute nutrient medium for five consecutive days, whereas organisms with much longer life cycles and less rapid growth form comparatively fewer hyphae in a period of five days, absorb and store away less food, and as a result show only a slight or no increase in production of fruit bodies.

In contrast to the general rule in the Phycomycetes as to asexual reproduction (Klebs, I3; Kauffman, 8; Pieters, 18), we find that in most of the Sphaeropsidales a vigorous growth of mycelium and a good development of fruiting bodies appear to go on at the same time and in the same concentration. The first fruiting bodies generally appear at the point of the initial transfer of the fungus. These fruit bodies are surrounded by actively growing hyphae the protoplasm of which is undergoing certain changes preparatory to pycnidium-formation. Klebs (Io) states that even in the Ascomycetes and the Imperfecti a cessation of growth and a subsequent lack of food are essential prerequisites for reproduction. But the examples given by him are relatively few, and apply to simpler reproductive bodies; consequently the results obtained with them are to be interpreted from a simpler combination of conditions. The factors which bring about a cessation of mycelial development tend, apparently, on the face of these observations, to check, rather than to stimulate, asexual reproduction in the Sphaeropsidales.

A number of experiments show that in the Sphaeropsidales vegetative growth and asexual reproduction are parallel within wide limits. Let us first consider the complete withdrawal of food from a normally grown mycelium. Regardless of whether the cultures were grown in the standard medium or in the solution sixteen times the usual concentration, a complete withdrawal of food gave rise, in most cases, to fewer fruit bodies. than its constant presence. This is because of the fact that a mycelium from which the food is withdrawn gradually ceases its growth, or else grows very slowly. Since the newly forming pycnidia are nourished by the reserve food of the mycelium when the external food supply is exhausted, and since this reserve food supply, no matter how well the mycelium may have been nour- 
ished, is not inexhaustible, the quantity of the fruit bodies tends to be limited. This is especially true in case of such forms as Kellermania yuccagena, Stagonospora gigantea, Steganosporium acerinum, etc., which have very large spores rich in protoplasm and in reserve food. When, however, a mycelium, which is well nourished in a nutrient solution of high concentration, is washed and transferred to a weak medium, a large number of organisms exhibit a sharp increase in their reproduction because, in order that the effect of the stimulus may show (as pycnidia), there must be enough food for their development, in addition to the stimulating effect of the sudden removal of food. Even very weak concentrations of food, furnished just when they are needed the most, increase the quantity of fruiting bodies very remarkably, of ten as much as the higher concentrations. Apparently in such cases only a comparatively slight amount of food is required, and the mycelium derives it with equal ease either from solutions of high or of low concentration. The fact that young pycnidia require a continuous food supply for their best development is proved by the behavior of Ascochyta nymphaeae, Endothia parasitica, and Cytosporella mendax. When transferred from the nutrient solution to distilled water, certain parts of the fruit bodies of these organisms are eliminated entirely, and thus the food supply is economized. The first named of these fungi fails to form pycnidial walls on most of its fruit bodies, the spores appearing either in small separate pycnidia or in naked masses. When transferred from distilled water back to food, pycnidial walls and stromata reappear. Stevens and Hall (24) found that when the spores of two species of Septoria were plated sparsely, pycnidia were obtained in the cultures, while, if planted densely, the pycnidial walls were eliminated and hyphomycetous spores appeared instead of pycnidia. Taubenhaus (25) observed that fruit bodies in Lasiodiplodia tubericola and Diplodia gossypii may be borne singly or in stromata, or they may be cespitose when growm in artificial cultures. While he does not analyze the causal factors, the quality and the quantity of the food supply may very likely be of great importance in these variations. Similarly, the stromata of Endothia parasitica may be eliminated under certain conditions as can be surmised from the description of Shear, Stevens, and Tiller (23) that "small pustules with spore masses occurred," and that these spore masses were "minute, very numerous." According to Anderson (I) the stroma in Endothia parasitica does not precede but follows the initial stages in the development of pycnidia. If this statement is true, although Shear, Stevens, and Tiller did not find it to be so in every case, then it becomes easier to conceive how a limited food supply may eliminate such less essential parts as stromata. Another example may be given here to illustrate the same point from a different angle: Stagonospora collapsa, which normally produces its pycnidia singly, gave rise to a number of well developed stromata when transferred from a weaker solution to a high concentration of food. Here, then, large amounts of available food were necessary for full stromatic development. 
If we now examine columns IV and VI of table 5, we shall see that a number of organisms when grown submerged in either the standard or the concentrated nutrient solutions and then transferred to distilled water, gave rise to very few fruit bodies. When, however, after this period of starvation they were transferred to the standard nutrient solution, a sharp increase took place in their fructification. Table 8 illustrates this point very well. Apparently the cultures formed pycnidium-initials when transferred to distilled water, but a lack of food hindered their further development. A total absence of food may be a stimulus, but unless food, even in a very dilute form, is furnished to the mycelium, the effect of the stimulus remains imperfect.

The results tabulated in column II of table 7 show that twelve organisms yielded a hundred percent fruit-body formation when they were transferred from the standard medium to the solution sixteen times the usual concentration. Ascochyta nymphaeae, which failed to form a single pycnidium when kept constantly in the high concentration, covered every available spot of the substratum with pycnidia after it was transferred from the low concentration to the high concentration of food. It appears that the protoplasm of the mycelium, after a period of vegetative growth in the standard solution, undergoes certain changes which favor the asexual reproduction more than formation of sterile mycelium; then, upon being transferred to a new condition, these changes persist, and even lead to a richer fruiting. But what about those organisms which remained unaffected, or even showed a decreased reproduction? Of course we can not expect all the organisms to exhibit such finely adjusted balance to the physiological factors as to respond to them with mathematical precision. The quality and the quantity of the nutrient medium used are not, and can not be, just as well suited for one organism as for another, nor can they be capable of maintaining an exactly harmonious balance between growth and pycnidium-formation in all fungi. Endothia parasitica, which showed an actual decrease of pycnidia when transferred to the high concentration, gave rise to a very large number of fruit bodies, provided that it was first grown submerged in the high concentration and then was washed and transferred to distilled water, kept there until the fruit bodies began to form, and then transferred directly to the high concentration again. The starving period apparently started a very large number of pycnidium-initials, which matured readily under the influence of the rich food. Thus a period of starvation followed closely by a period of rich feeding induces a maximum fructification.

The carrying-over effect of the mycelium, as well as the ability of a fungus to utilize unfavorable nutrient solutions to best advantage when given the proper environment, can be found well illustrated in table 9 . Fungi which failed to fruit in solution $B$, and made only a poor vegetative growth, formed their fruit bodies in much greater abundance when they were thoroughly washed and transferred to solution $A$. Certain potentiali- 
ties were acquired by the mycelium as a result of this stimulation and were carried over to solution $A$ in the protoplasm of the hyphae. But why did solution $B$ inhibit reproduction if it contained such a stimulus for fruiting? It is a well established principle (Klebs, I3) that too heavy concentrations of foods may prove inhibitory to reproduction in many organisms; also the presence of certain unfavorable factors may arrest the beneficial effect of other substances. After these inhibitory substances are washed off from the surface of the hyphae, and those present in the protoplasm are largely neutralized or converted by the assimilation of more favorably balanced nutrient substances, then the stimulus becomes effective. But not all the organisms exhibited the above-described reaction when transferred from solution $B$ to solution $A$. Perhaps the influence of solution $B$ carried over in the mycelium was too intense for these organisms, and hence could not be overcome by the favorable factors. The positive influences, just as the negative ones, may be carried over in various degrees of intensity, as illustrated in column VI of table 9. When the organisms were transferred from solution $A$ to solution $B$, fourteen of them were able to form fruit bodies as against six in the checks. The different potentialities acquired by these cultures during their vegetative growth in the more favorable medium partially or wholly overcame the inhibiting influence of solution $B$. Often the struggle between these two influences lasts long enough for a fair number of pycnidia to appear, but the unfavorable medium, because of its larger quantity and constant supply, eventually overcomes the opposing influences, and the fruiting comes to a halt. In other cases the initial vigor is not strong enough to promote the formation of even a single pycnidium. A different type of reaction which should be observed here is the phenomenal increase in the number of pycnidia of some organisms after a transfer from solution $A$ to solution $B$. Apparently the stimulus in this case is carried in solution $A$, and the second solution gives it an opportunity for expression.

\section{SUMmaRY}

I. Twenty organisms belonging to the order Sphaeropsidales were used in these experiments.

2. An especially favorable culture medium was devised; all the twenty organisms produced pycnidia readily on it.

3. A method, which made it possible to wash and completely free the cultures from one solution, and to transfer them to another one as of ten as it was desired, was developed and used exclusively throughout the work.

4. When light was excluded, two organisms failed to form pycnidia, twelve showed a reduced reproduction, while the remaining six were unaffected.

5. A temperature of $30^{\circ} \mathrm{C}$. generally induced a better pycnidium-production in spite of the absence of light, and in the case of one organism, which failed to fruit in the dark and at room temperature, it replaced the 
effect of light. A constant temperature of $8^{\circ} \mathrm{C}$. inhibited pycnidiumformation in only nine organisms in spite of the fact that light was excluded. In the presence of light, however, all the organisms were able to form pycnidia at a constant temperature of $8^{\circ} \mathrm{C}$.

6. A decreased supply of oxygen suppressed fruiting in three organisms, reduced it in eleven, while six remained indifferent.

7. Adsorption was found to be no controlling factor in growth or reproduction so long as an abundant supply of moisture was present.

8. Eight organisms fruited when submerged as well as on the surface; three formed pycnidia but failed to mature the spores, and nine fruited only on the surface of the nutrient solution.

9. Solidity of substratum is a factor in so far as a support is necessary for the mycelium and to bring it up to the air, and possibly to increase foodconcentration by exercising a negative adsorption.

I0. Generally a higher food-concentration produces more numerous pycnidia. Rich hyphal growth and pycnidium-development are parallel within a very wide range.

I I. A sudden complete withdrawal of food from a mycelium grown in a very rich solution is not, in most cases, conducive to better reproduction. If, however, such a mycelium is transferred to a dilute nutrient solution instead of to distilled water, a much better reproduction follows.

12. The sudden increase of food-concentration upon a mycelium grown in a more dilute solution is the condition most favorable to pycnidiumformation.

13. If a mycelium grown in a weak nutrient solution is transferred to a fresh supply of the same solution for five consecutive days, the effect, in many cases, approaches that of the highly concentrated nutrient medium.

14. Osmotic pressure is not a factor in growth and reproduction of these organisms.

15. No evidence of auto-intoxication was seen in any of the cultures.

16. A richly fed mycelium, after a subsequent period of starvation, if transferred to a dilute nutrient solution, gives rise to a great abundance of fruit bodies.

I7. The mycelium may acquire certain tendencies which may not manifest themselves unless they are subjected to the action of changed environmental factors.

Cryptogamic Laboratory,

DepartMENT OF Botany, UNIVERSITY OF MichigAN

\section{LITERATURE CITED}

I. Anderson, P. J. Morphology and life history of chestnut blight fungus. Comm. Invest. Contr. Chestnut Blight Dis., Penn. Bull. 7. 1913.

2. Arthur, J. C. The movement of protoplasm in coenocytic hyphae. Annals Bot. II: 49r. 1897 . 
3. Brefeld, O. Botanische Untersuchungen über Myxomyceten und Entomophthoreen. Heft 6.1884 .

4. Coons, G. H. Factors involved in the growth and the pycnidium formation of Plenodomus fuscomaculans. Jour. Agr. Res. 5: 713. I9I6.

5. DeVries, $\mathbf{H}$. Ueber die Bedeutung der Circulation und der Rotation des Protoplasmas für den Stofftransport in der Pflanze. Bot. Zeit. 43: I. 1885.

6. Falck, R. Die Bedingungen und die Bedeutung der Zygotenbildung bei Sporodinia grandis. Beitr. Biol. Pf. 8: 213. I901.

7. Guilliermond, A. The yeasts, p. II4. English transl. by F. W. Tanner. I920.

8. Kaufman, C. H. A contribution to the physiology of the Saprolegniaceae, with special reference to the variations of the sexual organs. Annals Bot. 22: 36I. I 908 .

9. Klebs, G. Über die Vermehrung von Hydrodictyon utriculatum. Flora 73:35I. I890.

Io. - - Die Bedingungen der Fortpflanzung bei einigen Algen und Pilzen. I896.

I I. - Zur Physiologie der Fortpflanzung einiger Pilze. Jahrb. Wiss. Bot. 32: I. I898.

12. - - Zur Physiologie der Fortpflanzung einiger Pilze. Jahrb. Wiss. Bot. 33: 513. 1899.

13. - Zur Physiologie der Fortpflanzung einiger Pilze. Jahrb. Wiss. Bot. 35: 80. 1900.

14. Leininger, H. Zur Morphologie und Physiologie der Fortpflanzung von Pestalozzia palmarum. Inaug. Dissert. Heidelberg, I9I I.

15. Lendner, A. Des influences combinées de la lumière et du substratum sur le développement des champignons. Ann. Sci. Nat. Bot. VIII, 3: I. 1896.

16. Leonian, L. H. Fusarium wilt of Chili pepper. N. M. Coll. Agr. Mech. Arts Bull. I2r. 1919 .

17. - - Studies on the Valsa apple canker in New Mexico. Phytopath. I1: 236. I921.

18. Pieters, A. J. The relation between vegetative vigor and reproduction in some Saprolegniaceae. Amer. Jour. Bot. 2: 529. I915.

19. Raciborski, M. Über den Einfluss äusserer Bedingungen auf der Wachstumweise des Basidiobolus ranarum. Flora 82: 197. I896.

20. Raulin, J. Études chimiques sur la végétation. Ann. Sci. Nat. Bot. V, II: 93 . 1869.

21. Raybaud, L. Influence du milieu sur les champignons inférieurs. Rev. Gén. Bot. 24: 392. 1912.

22. Schostakowitsch, W. Über die Bedingungen der Conidienbildung bei Russthaupilzen. Flora 81: 362 . I 895 .

23. Shear, C. L., Stevens, N. E., and Tiller, R. J. Endothia parasitica and related species. Bull. Bur. Pl. Ind. 380 . 1917.

24. Stevens, F. L., and Hall, J. G. Variations of fungi due to environment. Bot. Gaz. 48: I. 1899 .

25. Taubenhaus, J. J. The probable non-validity of the genera Botryodiplodia, Diplodiella, Chaetodiplodia, and Lasiodiplodia. Amer. Jour. Bot. 2:324. 1915.

26. Wakefield, Elsie M. Some factors controlling fruit formation in Hymenomycetes. Naturw. Zeitschr. Forst. Landw. 7: 521. 1909. (Abstr.) Exp. Sta. Rec. 22: 330. I9I0. 